\title{
Micropropagation of Turkestan Soap Root Allochrusa gypsophiloides - Natural Source of Saponins
}

\section{Valentina Mursaliyeva (D) 1, ${ }^{*}$, Akjunus Imanbayeva²}

\author{
${ }^{1}$ Institute of Plant Biology and Biothechnology, Almaty, Kazakhstan \\ ${ }^{2}$ Mangyshlak Experimental Botanical Garden, Aktau, Kazakhstan
}

\begin{abstract}
Allochrusa gypsophiloides or Turkestan soap root (TSR), which is endemic to Central Asia, is a valuable saponin-bearing technical and medicinal plant. The purpose of this study was to develop in vitro mass propagation for the conservation of endangered species. Node explants were induced to regenerate adventitious shoot buds on Murashige and Skoog medium (MS) supplemented with different concentrations of 6benzylaminopurine (BAP) and/or kinetin in combination with naphtylacetic acid (NAA). The maximum number of shorter shoots per explant $(16.8 \pm 3.1)$ was recorded on MS contained $0.5 \mathrm{mg} / \mathrm{L}$ BAP and $0.5 \mathrm{mg} / \mathrm{L}$ NAA after one month cultivation. For elongation, obtained shoot conglomerates were transfered for hormone-free MS. The cultivation of initial explants on MS with kinetin led to a three-fold reduction in the number of shoots characterized by a maximum length and clearly defined internodes (without the stage of elongation). Micropropagation was achieved by cutting obtained shoots and adventitious shoot induction. The maximal shoot proliferation (62 \pm 6.9 ) on MS $0.5 \mathrm{mg} / \mathrm{L} \mathrm{BAP}+1.0 \mathrm{mg} / \mathrm{L}$ kinetin $+0.5 \mathrm{mg} / \mathrm{L} \mathrm{NAA}$ was obtained. Shoots of about $0.5 \mathrm{~cm}$ required to elongation before rooting on the liquid $1 / 2$ MS medium contained NAA or IBA. In both cases, auxin concentration $2.0 \mathrm{mg} / \mathrm{L}$ induced maximal rooting $(58 \%$ and $60 \%$, respectively) at 20-day's incubation. Type of auxin was influenced most on root quality (thickness, color, branching) than on their frequency and number.
\end{abstract}

\section{ARTICLE HISTORY}

Received: September 30, 2019

Revised: December 24, 2019

Accepted: February 03, 2020

\section{KEYWORDS}

Allochrusa gypsophiloides,

Turkestan soaproot,

Saponin-bearing plant,

Adventitious shoot,

Micropropagation

\section{INTRODUCTION}

Turkestan soaproot (TSR) Allochrusa gypsophiloides (Regel) Schischk. (Acanthophyllum gypsophiloides Rgl.) endemic Central Asian species of the Caryophyllaceae family is herbaceous polycarpic perennial with monocyclic development. The underground part of the plant is represented by a strong taproot, aerial part - highly branched, spherical bush "tumbleweed." The species has a relatively limited area, it grows only in the western Tien Shan and Pamir-Alae at foothill desert loess steppes, dry slopes of rivers, on gravelly slopes at an altitude of 400-1300 meters above sea level [1]. TSR, which has been known as a valuable source of saponin on the territory of the republics of Central Asia and Kazakhstan, has been

CONTACT: Valentina Mursaliyeva $₫$ gen_mursal@mail.ru @ Institute of Plant Biology and Biothechnology, Almaty, Kazakhstan 
exported for a long time [2]. Annual planned volumes of collecting dry roots reached 700 - 800 tones. As a result of the intensive and unsystematic harvesting of TSR brings it to the list of rare species with a strongly decreasing population and recorded in the Red Book of Kazakhstan from 1981 [3]. The analysis of the literature suggests that TSR is an economically important native -saponin-bearing plant. Compared with other saponin-bearing plants, TSR differs by the elevated levels of triterpenoid saponins (oleanane-type, up to 30\%) in the roots. Among them, acanthophyllosides B, C, and D (derivatives of gypsogenin and quillaic acid) are isolated in their pure form $[4,5]$. The evaluation of activities of TSR saponins has revealed their high foaming surface (foaming ratio 1:6660) and significant hemolytic activities (HI 3333) for aqueous and ethanolic extracts from TSR roots [6]. TSR is one of the most valuable medicinal plants in the Kazakhstan flora, which is included in the official pharmacopoeia and TSR triterpenoid saponin is used as spit, diuretic, laxative and tonic, and as a part of oral herbal remedies [7]. Recent studies have revealed a high immunostimulating [8], antiviral [9] and anticancer [10] activities of TSR extracts based on the ability of TSR saponins to enhance the immunogenicity of different antigens. Currently, however, TSR natural resources are extremely exhausted. A review of previous studies of ecological state of endemic species showed that small natural populations and their high sensitivity to human impact, low rates and a long period of self-reproduction obstruct natural regeneration of natural TSR populations [11]. Naturally, TSR propagates only by seeds. However, seed yield is very low and field seeds germination greatly depends on the growth conditions and does not exceed 18 to $20 \%$. In natural conditions plant growth and development of TSR are often suppressed by the surrounding vegetation, quickly drying up the soil in the spring and summer period. Only a small part of individuals of the population reaches the reproductive phase of development [2]. In vitro micropropagation is widely used to obtain high-quality planting material for saponin-containing plants such as Gypsophila paniculata [12], Saponaria officinalis [13]. Studies on tissue culture of $A$. gypsophiloides have not previously been conducted. In this regard, the research aimed was to develop based on the in vitro technique effective methods for the accelerated propagation of TSR.

\section{MATERIAL and METHODS}

\subsection{Plant material and adventitious shoot induction}

To obtain donor plants, A. gypsophiloides seeds were collected from the natural populations within the territories South-Kazakhstan region and planted in the experimental field in early spring. Young shoots long 3-4 cm from two-year-old plants at the vegetation stage were cut in April - July for introduction in vitro. After isolation, the collected material was washed thoroughly with running water. In the laminar air-cabin, the shoots were dipped in $70 \%$ ethanol, followed by immersion in a $0.1 \%$ solution mercuric chloride for $10 \mathrm{~min}$. The explants were finally washed thrice with sterilized water and were trimmed to $1.0-1.5 \mathrm{~cm}$ long segments before its transfer to tuber with $30 \mathrm{~mL}$ of a solidified culture medium. MS salts [14] supplemented with 3\% sucrose and 0,6\% agar bacteriology grade (AppliChem, Germany) were used to prepare the medium. The $\mathrm{pH}$ was adjusted to 5,8 before autoclaving at $121^{\circ} \mathrm{C}$ for 20 min. For adventitious shoot induction, the basic solid MS was supplemented by BAP and/or kinetin in combination with auxin NAA.

Variants: MS 1) 0,5 mg/L BAP + $1.0 \mathrm{mg} / \mathrm{L}$ kinetin + $0.5 \mathrm{mg} / \mathrm{L}$ NAA; MS 2) $0,1 \mathrm{mg} / \mathrm{L}$ $\mathrm{BAP}+1.0 \mathrm{mg} / \mathrm{L}$ kinetin + 0.5 mg/L NAA; MS 3) $0.5 \mathrm{mg} / \mathrm{L} \mathrm{BAP} \mathrm{+} 0.5 \mathrm{mg} / \mathrm{L}$ NAA, MS 4) 1.0 $\mathrm{mg} / \mathrm{L}$ kinetin $+0.5 \mathrm{mg} / \mathrm{L}$ NAA.

Ten replicated (culture tubers) in each treatment were used in two repetitions. All cultures at $25 \pm 2{ }^{\circ} \mathrm{C}$ in a culture room with a $16 / 8 \mathrm{~h} \mathrm{light/dark} \mathrm{photoperiod} \mathrm{under} \mathrm{cool} \mathrm{white} \mathrm{fluorescent}$ light were maintained. The frequency of shoot regeneration as the percentage of responding 
explant from the total explants was evaluated. The number of regenerated shoots was defined as the number of adventitious shoot buds regenerated and elongated on each primary explants 30 day after culture ( 0 passage).

\subsection{Multiplication stage and elongation stage}

The proliferated shoots were harvested as they reached 5-7 cm length and cut into 1.0-1.5 $\mathrm{cm}$ long micro-cutting and cultured on MS augmented with BAP or kinetin at concentration 1.0 $\mathrm{mg} / \mathrm{L}$ combined with $0.5 \mathrm{mg} / \mathrm{L}$ NAA (I passage).Each treatment consisted of three replicated (culture vessels) with 10 node explants per vessel. All culture jars were kept at the same conditions of adventitious shoot induction stage. Micropropagation rate $(\mathrm{Mr})$ as the total number of adventitious shoots in the variant of medium, divided by the number of passaged node explants was defined. Repetitive shoot multiplication was achieved on the best shoot multiplication medium. Cultures were transferred to freshly prepared medium monthly (II passage). Multiplied shoots were excised from their clusters at length of 1.0-1.2 cm and allowed to elongated on growth regulator free MS.

\subsection{In vitro shoot rooting induction}

For induction roots elonged to about $4 \mathrm{~cm}$ shoots were transferred to half strength liquid medium $(1 / 2 \mathrm{MS})$ containing of NAA or indole-butyric acid (IBA) at concentrations of $0.5,1.0$, $2.0,3.0 \mathrm{mg} / \mathrm{L}$, in control - on $1 / 2 \mathrm{MS}$ free from growth regulator. The three replicated experiments with ten shoots in each were carried out. All cultures in a standard culture room with a 16/8h light/dark photoperiod were maintained. The root induction percentage and root length at the end of the month cultivation were recorded. All experiments were designed in a completely randomized design and obtained data were expressed as the mean values \pm standard error. Differences were considered statistically significant at $\mathrm{p} \leq 0.05$.

\section{RESULTS and DISCUSSION}

\subsection{Activation of axillary bud growth and shoot regeneration}

It was found that the nodal explants vitality depended on the time of cutting them from donor plants. Isolation plant material in spring (April, May) provided a high survival rate under cultivation (78\%-90\%). The viability of explants cut at the end of active vegetation of field plants (August) was very low and did not above $20 \%$. In this case during cultivation, the primary explants were darkened and gradually were necrotized by negative effects of oxidation products of phenolic compounds released from plant tissue into the nutrient medium. A. gypsophiloides has shoots with oppositely arranged leaves in the node. The bud set in the axil of each leaf and it gives axillary shoots during germination. Activation of axillary bud growth was observed on 3-4 culture's day and led to the two adventitious shoots per original explant cultured on the inducing medium (Figure 1-A, B). It was revealed that the type of cytokinin in medium influenced the morphology, quality, and quantity of regenerated shoots. The explants cultured on MS medium supplemented with kinetin as cytokinin produced normal shoots long $4-5 \mathrm{~cm}$ with 4-6 nodes and leaves after one month cultivation (Figure 1-C), whereas BAP addition caused the growth a lot of shortened shoots with densely located internodes and leaves (Figure 1-D). In the variant with BAP supplement combined with kinetin regeneration of shoots with normal morphology and size was revealed (Figure 1-E). A significant effect of the growth regulators of the medium on the number of regenerated shoots was established (Table 1). The number of regenerated shoots per explant was significantly higher on MS 3 with $0.5 \mathrm{mg} / \mathrm{L}$ BAP $+0.5 \mathrm{mg} / \mathrm{L}$ NAA, but the length did not grow to upper $0.6 \mathrm{~cm}$. For further growth and elongation, the initiated shoot conglomerates were a need to transfer on a hormone-free medium. The cultivation of explants on MS 1, MS 2, MS 4 led to the regeneration of longer shoots, but their number was about three times less than on MS 3. The significant influence of 
the type of cytokinins on the node number located on the initiated shoot was revealed. The shoots regenerated on MS 4 with $1.0 \mathrm{mg} / \mathrm{L}$ kinetin $+0.5 \mathrm{mg} / \mathrm{L} \mathrm{NAA}$ had longer internodes. Additional supplement BAP into the medium resulted in appearance of additional nodes and shorter internodes on the shoot.
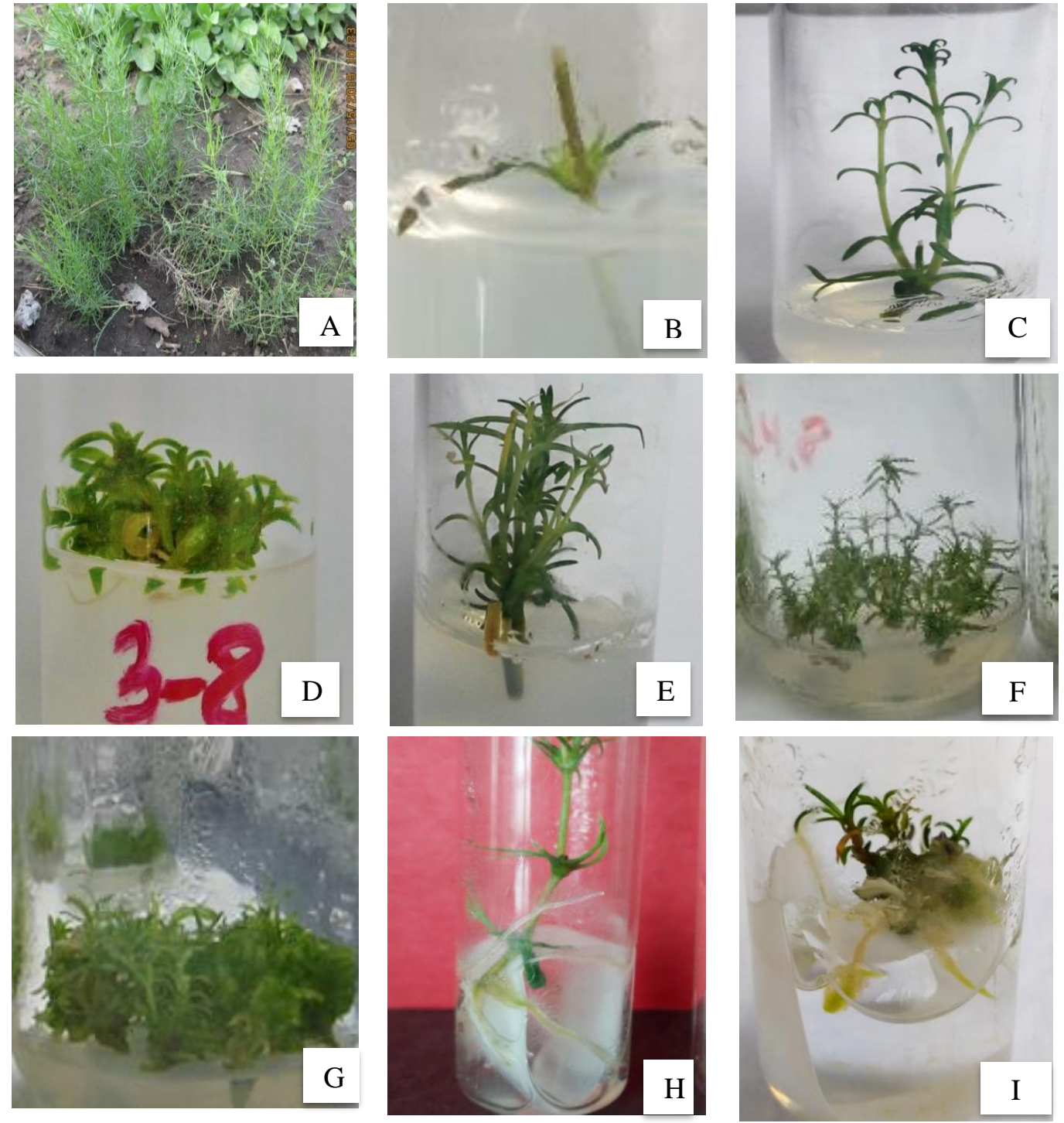

Figure 1. Allochrusa gypsophiloides: A. Explant source; B. Nodal explant, 3-day culture; C. Axillary shoots growth on MS $1 \mathrm{mg} / \mathrm{L}$ kinetin $+0.5 \mathrm{mg} / \mathrm{L}$ NAA, 0 passage; D. Adventitious shoot on MS $0.5 \mathrm{mg} / \mathrm{L}$ BAP $+0.5 \mathrm{mg} / \mathrm{L}$ NAA; E. Shooting on MS $0.5 \mathrm{mg} / \mathrm{L}$ BAP $+1.0 \mathrm{mg} / \mathrm{L}$ kinetin $+0.5 \mathrm{mg} / \mathrm{L}$ NAA; F. Inoculation on multiplication medium, I passage; G. Shoot proliferation, II passage; H. Rooting on $1 / 2 \mathrm{MS}+1 \mathrm{mg} / \mathrm{L}$ IBA; I. Rooting on $1 / 2 \mathrm{MS}+1 \mathrm{mg} / \mathrm{L}$ NAA

\subsection{Adventitious shooting and multiplication}

As shown in Figure 1-F, each explant from initiated shoot transferred to micropropagation medium was multiplied to 3-6 shoots at the first passage. At this stage, shoots grew and the node number on the shoot was increased. Micropropagation was achieved both by lateral shoot branching and as a result of laying additional buds at the base of the main shoot, i.e. by adventitious shoot induction (Figure 1-G). The mean number of adventitious shoots propagated during the one passage was maximal on MS 1 supplemented with $0.5 \mathrm{mg} / \mathrm{L} \mathrm{BAP}+1.0 \mathrm{mg} / \mathrm{L}$ kinetin $+0.5 \mathrm{mg} / \mathrm{L}$ NAA (Table 2). 
Table 1. Effects of different combinations of plant growth regulators on shoot regenaration from nodal segments of Allochrusa gypsophiloides 30 day after culture

\begin{tabular}{|c|c|c|c|c|c|c|c|}
\hline \multirow[t]{2}{*}{$\begin{array}{c}\text { Ms } \\
\text { Medium }\end{array}$} & \multicolumn{3}{|c|}{$\begin{array}{c}\text { Plant Growth } \\
\text { Composition mg/L }\end{array}$} & \multirow{2}{*}{$\begin{array}{c}\text { Shoot } \\
\text { Regeneration } \\
\%\end{array}$} & \multirow{2}{*}{$\begin{array}{c}\text { Mean Number of } \\
\text { Shoots } \\
\text { Per Explant }\end{array}$} & \multirow{2}{*}{$\begin{array}{l}\text { Shoot } \\
\text { Length } \\
\mathrm{cm}\end{array}$} & \multirow[t]{2}{*}{$\begin{array}{l}\text { Number of } \\
\text { Node }\end{array}$} \\
\hline & BAP & Kinetin & NAA & & & & \\
\hline MS 1 & 0.5 & 1.0 & 0.5 & 80 & $6.33 \pm 0.60 \mathrm{a}$ & $2.2 \pm 0.26 \mathrm{a}$ & $7.71 \pm 0.91 \mathrm{a}$ \\
\hline MS 2 & 0.1 & 1.0 & 0.5 & 70 & $5.75 \pm 0.43 \mathrm{a}$ & $2.25 \pm 0.62 \mathrm{a}$ & $6.25 \pm 1.54 \mathrm{ab}$ \\
\hline MS 3 & 0.5 & - & 0.5 & 85 & $16,80 \pm 3,15 b$ & $0.65 \pm 0,08 b$ & - \\
\hline MS 4 & - & 1.0 & 0.5 & 85 & $5.00 \pm 0.82 \mathrm{a}$ & $2.85 \pm 0.26 \mathrm{a}$ & $4.85 \pm 0.88 b$ \\
\hline
\end{tabular}

Note: mean values followed by the same letters in columns do not differ at the significance level $\mathrm{p} \leq 0.05$

Table 2. Multiplication rate of Allochrusa gypsophiloides in depending on the growth regulators composition of MS medium

\begin{tabular}{ccccccc}
\hline Medium & \multicolumn{3}{c}{$\begin{array}{c}\text { Plant Growth } \\
\text { Composition } \mathrm{mg} / \mathrm{L}\end{array}$} & & $\begin{array}{c}\text { Number of } \\
\text { Adventitious Shoots } \\
\text { on Passage* }\end{array}$ & $\begin{array}{c}\text { Multiplication Rate for } \\
\text { Two Passage }\end{array}$ \\
\cline { 2 - 4 } & BAP & Kinetin & NAA & & $62.0 \pm 6.96 \mathrm{a}$ & 11.8 \\
\hline MS 1 & 0.5 & 1.0 & 0.5 & & $25.4 \pm 4.07 \mathrm{~b}$ & 4.6 \\
MS 2 & 0.1 & 1.0 & 0.5 & & $41.67 \pm 4.33 \mathrm{ab}$ & 7.0 \\
MS 4 & - & 1.0 & 0.5 & & 41.5 \\
\hline
\end{tabular}

Note: * result obtained from 10 initial micro-cutting; mean values followed by the different letters in columns differ at the significance level $\mathrm{P} \leq 0.01$

The inducing action of MS1 did not significantly differ from a similar effect MS 3 but exceeded the effect of MS 2 with a high significance level. Using the method of micro-cutting and adventitious shooting in vitro allowed to obtain plant material in mass quantity: above 100 plant-regenerants from the initial explants at three passages or 3-month cultivation on induced mediums.

Table 3. Effect of different concentration of NAA and IBA in $1 / 2$ MS medium on rooting of Allochrusa gypsophiloides

\begin{tabular}{ccccc}
\hline Growth Regulator mg/L & $\begin{array}{c}\text { Number of } \\
\text { Rooting Shoots } \%\end{array}$ & Length of Root & $\begin{array}{c}\text { Cultivation Length } \\
\text { Day }\end{array}$ & $\begin{array}{c}\text { Distinctive } \\
\text { Features }\end{array}$ \\
\hline 0 & 10 & $1.25 \pm 0,53 \mathrm{a}$ & 56 & \\
0.5 NAA & 10 & - & & root II order, callus \\
1 NAA & 47 & $2.15 \pm 0.11 \mathrm{a}$ & 20 & \\
2 NAA & 58 & $1.75 \pm 0.18 \mathrm{a}$ & 20 & root II order \\
3 NAA & 10 & - & 40 & root II order \\
0.5 IBA & 20 & $1.40 \pm 0.07 \mathrm{a}$ & 30 & \\
1 IBA & 33 & $2.50 \pm 0.35 \mathrm{a}$ & 20 & 20 \\
2 IBA & 60 & $1.33 \pm 0.24 \mathrm{a}$ & 30 & \\
3 IBA & 20 & - & 205
\end{tabular}

Note: mean values followed by the same letters in columns do not differ at the significance level $p \leq 0.05$

\subsection{In vitro rooting induction}

It was revealed that the rooting induction continued a long period from 20 days to two months, depending on the composition of liquid MS (Table 3). The stimulating effect of NAA and IBA treatments was dependent on their doses in the medium. In both cases, auxin concentration $2.0 \mathrm{mg} / \mathrm{L}$ induced maximal rooting (58 \% and $60 \%$, respectively) at 20-day's incubation in the liquid $1 / 2 \mathrm{MS}$. An increase in the auxin concentration to $3 \mathrm{mg} / \mathrm{L}$, as well as a decrease it's to $1 \mathrm{mg} / \mathrm{L}$ and $0.5 \mathrm{mg} / \mathrm{L}$, reduced root formation on aseptic shoots by three to five 
times. The morphology of the induced root was influenced by the type auxin used for treatment. Root induced on the IBA medium was thinner and lighter-colored than root obtained on medium supplemented NAA (Figure 1-H, I).

\section{CONCLUSION}

In this study, it can be concluded that TSR has high regenerative potential in vitro and micropropagation is an effective alternative breeding method for this endemic plant. The node segment is optimal explant for successful direct shoot regeneration on induced medium supplemented by BAP and/or kinetin in combination with auxin NAA. Cytokinin BAP induce mass regeneration of adventitious shoot clusters that need in elongation on hormone -free medium in several passages. This fact leads to increase length of whole cycle cultivation (from introduction to rooting regenerant) in 2-4 months. For the micropropagation stage, the addition of $1 \mathrm{mg} / \mathrm{L}$ kinetin $+0.5 \mathrm{mg} / \mathrm{L} \mathrm{NAA}$ is more preferable to obtain stronger and longer shoots that can be transferred to rooting medium without additional stage of elongation as in a case with BAP supplement. The effective rooting of shoots on MS medium with supplement auxin NAA or IBA at concentration $1 \mathrm{mg} / \mathrm{L}$ by 20 day's cultivation is achieved. The application of this micropropagation protocol will help to restore the endemic species without significant damage to its natural populations and in further scientific-practical use of the valuable natural saponin source.

\section{Acknowledgements}

The research was financially supported by the Ministry of Education and Science of Republic of Kazakhstan (program number BRO5236506).

\section{Orcid}

Mursaliyeva Valentina (D) https://orcid.org/0000-0003-4803-9169

\section{REFERENCES}

[1].Eisenman, S., Strume, L., Zaurov, D. (2012). Medical plants of Central Asia: Uzbekistan and Kyrgyzstan; Springer; New York, USA. ISBN 13: 9781461439110.

[2].Bespayev, S. (1966). Acanthophyllum gypsophiloides in Kazakhstan: morphology, taxonomy, phytosociology, testing in culture. Thesis on scient. degree of cand. biol. sci., Kazakh State University, Alma-Ata, 09.06.1966.

[3]. Red Data Book of the Kazakhstan (2014). 2rd ed; ArtPrintXXI, Astana, Kazakhstan, 2: 60.

[4]. Kondratenko, E., Putieva, Z., Abubakirov, N. (1981). Triterpenoid glycosides of plants of the family Caryophyllaceae. Chem. Nat. Comp., 17, 303-317. doi: 10.3762/bjoc.8.87

[5].Battger, S., Melzig, M. (2001). Triterpenoid saponins of the Caryophyllaceae and Illecebraceae family. Phytochem. Lett, 4 (2):59-68. doi: 10.1016/j.phytol.2010.08.003

[6]. Mursaliyeva, V., Kozhebayeva, Zh., Rakhimbayev, I., Gemejiyeva, N. (2016). Qualitative and quantitative analysis of saponins in Allochrusa gypsophiloides. KazNU Bulletin. Biol. series, 3(68), 115-123.

[7]. Grudzinskaya, L., Gemedzhieva, N. (2012). List of medicinal plants in Kazakhstan. Almaty, Kazakhstan. 55. ISBN: 978-601-80248-6-3.

[8].Tumagambetova, A., Alexyuk, P., Bogoyavlenskij, V., Zaitseva, E., Omirtaeva, M., Alexyur, M., Sokolova, N. (2017). Adjuvant activity of saponins from Kazakhstani plants on the immune response to subunit influenza vaccine. Archives of Virology, 162 (12), 38173826.

[9].Aleksyuk, P., Moldakhanov, E., Akanov, K., Anarkulova, E., Bogoiavlenskii, A. (2014). Standardization of saponin's drugs with antiviral activity. Inter. J. Appl. \& Fundam. Res., $6,80-81$. 
[10]. Man, S., Gao, W., Zhang, Y., Huang, L., Liu, C. (2010). Chemical study and medical application of saponins as anti-cancer agents. Fitoterapia, 81(7), 703-714. doi: 10.1016/j.fitote.2010.06.004

[11]. Gemejiyeva, N., Mursaliyeva, V., Mukhanov, T. (2016). Assessment of the current state of Allochrusa gypsophiloides (Regel) Schischk. natural populations in the SouthKazakhstan region. News of Nation. Acad. Sci. Rep. of Kazakhstan. Ser. Biol. and Medic., 1(313), 22-29. ISSN 2224-5308.

[12]. Barakat, M., Heba, E. (2011). In vitro culture and plant regeneration from shoot tip and lateral bud explant of Gypsophila paniculata L. J. Med. Plants Res., 5(15), 3351-3358.

[13]. Hussain, Md., Fareed, S., Ansari, S., Rahman, Md., Ahmad, L., Saeed, M. (2012). Current approaches toward production of secondary plant metabolites. J. Pharm. Bioall. Sci., 4(1), 10-20.

[14]. Murashige, T., Skoog, E. (1962). A revised medium for rapid growth and bioassays with tobacco tissue cultures. Physiol.Plan., 15, 473-497. 